\title{
Crime in Greater Los Angeles: Experiences and Perceptions of Local Urban Residents
}

\author{
Raqota Berger \\ Center for Criminal and Psychological Studies, Los Angeles, USA \\ Email: rberger@vcccd.edu
}

How to cite this paper: Berger, R. (2018). Crime in Greater Los Angeles: Experiences and Perceptions of Local Urban Residents. Current Urban Studies, 6, 260-277. https://doi.org/10.4236/cus.2018.62015

Received: June 9, 2018

Accepted: June 26, 2018

Published: June 29, 2018

Copyright (C) 2018 by author and Scientific Research Publishing Inc. This work is licensed under the Creative Commons Attribution International License (CC BY 4.0).

http://creativecommons.org/licenses/by/4.0/

\begin{abstract}
The area making up greater Los Angeles is the most populated region in the United States. With over 10 million residents in this largely urban county, we can only expect there to be some ongoing problems with crime and victimization. The current study collected self-reported data from local resident in regard to their personal experiences with crime and victimization. Relevant demographic information was collected to help with our understanding of which types of social groups may be more prone to being targeted for certain types of criminal acts. Information was also gathered to help better understand how Los Angeles area residents felt about crime in the region and how they felt about their own personal safety. Women were found to be more likely to know the perpetrators of crimes against them than the men. Middle Eastern and Black residents generally felt the most unsafe, while Asian residents felt the safest overall. Most of the respondents stated that they have been the target of one or more criminal acts since they have lived in the Los Angeles area, with the most common single type of crime being robbery. Additional findings add further to our knowledge about this important social problem spanning across this major urban territory.
\end{abstract}

\section{Keywords}

Urban Crime, Victimization, Perception of Crime, Crime Typologies

\section{Introduction}

Few Americans will get through life without being the target of some type of criminal act. Millions of Americans are violently victimized each year, and millions more have some type of property crime committed against them. Whitecollar crime has also skyrocketed in recent years and it is now almost expected that at some point in life someone will commit fraud, identity theft, or some 
other type of white-collar crime against you. Crime in American cities is also much higher than it is in other modernized societies. The homicide rate in Chicago, for instance, has been staggering over the last decade and it does not seem to be improving to any real extent. Many Americans fear living in urban areas due to their perceptions of crime and violence taking place in the nation's largest cities. This study focuses on the county of Los Angeles, California and may be of interest to professionals working in the fields of criminology, sociology, psychology, urban studies, or criminal justice.

Los Angeles is one of the most populated counties in the nation. The city of Los Angeles alone added over 18,600 new residents in 2017 (World Population Review, 2018). Los Angeles county now has over 10 million residents and is one of the most ethnically and culturally diverse counties in the nation (Stotzer, 2010). Crime in Los Angeles has not been improving in recent years. According to the Los Angeles Times (2016, December 30), crime across almost all major categories went up in Los Angeles from 2015 through 2016 (Chang \& Lau, 2016). The Chang and Lau (2016) report stated that statistics from the Los Angeles Police Department showed that robberies were up by $13 \%$, aggravated assaults were up by $10 \%$, property crime was up by $4 \%$, and car thefts were up by over $10 \%$. According to the Los Angeles Police Department homicide was up for the third straight year in a row (up 5\%) and 2016 saw 290 people murdered in Los Angeles alone (Chang \& Lau, 2016).

Easter (2017) reported that between 2010 and 2016 crime in Los Angeles county rose by $5 \%$, while crime across all of California declined by approximately the same amount. The report also noted that violent crime increased by $27 \%$, most notably in the city of Los Angeles where assaults went up by $60 \%$ (Easter, 2017). While some jurisdictions and cities saw increases in overall crime during this period (e.g., Torrance, Burbank, Lancaster, Long Beach, etc.), other cities saw declines in overall crime rates (e.g., Glendale, Inglewood, Santa Clarita, Palmdale, etc.; Easter, 2017). A comprehensive 2018 statistical report on crime in Los Angeles found that a person's chance of being victimized in Los Angeles is around 1 in 136. To place this in context, the same odds in the state of California are around 1 in 225 (Neighborhood Scout, 2018). According to the Neighborhood Scout (2018) report, there were 29,230 violent crimes in Los Angeles last year and 101,165 property crimes. This included 294 homicides, 2,386 rapes, 10,484 robberies, and 16,066 assaults. Property crimes during the same year included 16,050 burglaries, 19,024 motor vehicle thefts, and 66,091 thefts (Neighborhood Scout, 2018). Chang (2017) found that homicides rates in Los Angeles went down from 2016 to 2017 (from 289 to 271, 6\% decline). She also reported that during that same period overall crime in Los Angeles went up by $4 \%$, with robberies increasing by $6 \%$, aggravated assaults increasing by $5 \%$, and property crime increasing by $1 \%$ (Chang, 2017).

The current study has the intent of bringing forth contemporary information regarding crime and victimization in Los Angeles, California. Los Angeles is one 
of the largest cities in the nation and has the most populated county overall. Crime rates in Los Angeles exceed both the national average as well as the average in the state of California. There are many different reasons for these relatively high crime rates and scholars will argue different points of view about why this is (e.g., unemployment, poverty, immigration, homelessness, the breakdown of the family structure in urban areas, drug use, deficiencies in law enforcement personnel, and so forth). This study does not set out to address these issues as much as it does on crime itself, victimization, and the perceptions of local residents. The study hopes to highlight some basic trends in crime and victimization, as well as how local residents feel about living in Los Angeles and how safe or unsafe they perceive themselves to be. Crime in America's large cities has long been a major national problem. Los Angeles is a prime city to highlight for this type of investigation and cultural analysis.

\section{General Aim of the Study}

The general purpose of this study is to get a better sense of the types of crimes that Los Angeles area residents have been the victims of. The study has the goal of making clear distinctions between which types of crimes certain social groups are more likely to be the victims of (e.g., gender and ethnicity) and how this connects to larger economic factors (e.g., social class). One aim of the study is to make wider connections to crime rates across the greater Los Angeles area (e.g., violent, property, white-collar) and to then connect everything to the perceptions that local residents have about living in the Los Angeles area. The study will bring forth the feelings that residents have about crime today and whether they feel that crime is getting better or worse across the region. Another intention of the study is to highlight which crime categories seem to be the most prevalent and which types of crimes the participant residents have been the targets of. Analytic connections will be made to the data and to the wider crime rates collected across greater Los Angeles.

The current study will also place an emphasis on intimacy and crime, meaning how often the victims of crime personally know the perpetrators that caused them some kind of harm. Analysis will be given to the connections found between which types of crimes seem to involve personal acquaintances (e.g., family members, intimate partners, friends) and which types of crimes seem to involve perpetrators unknown to the victims. Age will also be looked at in regard to which types of crimes younger and older people are more or less likely to be the targets of. An additional intent of the study is to get a general sense of how local residents feel about living in the Los Angeles area (e.g., safety) and whether any notable distinctions can be made across populations (e.g., social class, gender, ethnicity). Crime in Los Angeles is among the worst in the nation. Those living in this regional area are at greater risk of being victimized in some kind of way compared to most people living in other areas across the state and across the nation. This study has the basic intent of adding to our general understanding of 
crime in and around Los Angeles, who is likely to be the target of certain types of crimes, and how local residents feel in general about living in this area. Wider connections will also be made to the literature and to current statistical data.

\section{Literature Review}

Los Angeles is widely known for its glamorous neighborhoods, rich celebrities, high fashion, expensive shopping, and fancy restaurants. But there is another side to Los Angeles that is not often talked about or covered in the media. This large city also has major problems with homelessness, gangs, drugs, violence, and every type of crime. Crime in Los Angeles exceeds both the state averages and the national averages. For example, violent crime in Los Angeles is 61\% higher than the California average and is $86 \%$ higher than the national average (Area Vibes, 2018). One argument for these high rates of crime is that many residents in the Los Angeles area are transient or new to the area and do not have a vested interest in their neighborhoods. Moore and Recker (2017) argued that crime in urban counties in the United States, such as in Los Angeles, is largely due to a lack in social capital. They found in their research that when community residents in urban areas do not have adequate social networks built on trust and reciprocity that both violent and property crimes are higher than they otherwise would be. This finding fits well with what other researchers have found regarding social capital and social control, urban crime and routine activities, rail transit, and cultural assimilation (Browning, Calder, Boettner, \& Smith, 2017; Burchfield \& Silver, 2013; MacDonald, Hipp, \& Gill, 2012; Ridgeway \& MacDonald, 2016).

Burchfield and Silver (2013) found in their research on Latino Los Angeles residents that the more social disorganization there is in the community the more likely they are to be victimized and the higher overall crime rates are. As an example, they found that the more social ties and collective efficacy that Latino residents have the less likely they are to be robbed and victimized in general. Ridgeway and McDonald (2016) studied rail transit in Los Angeles and found that although rail transit itself may not have a major effect on overall crime it can create hotspots where people may be more easily victimized. They, along with other researchers, also found that it allows for a more transient population, which has been shown to be associated with increases in certain types of criminal activities (e.g., robberies, theft, etc.; Burchfield \& Silver, 2013; Moore \& Recker, 2017; Ridgeway \& MacDonald, 2016). Browning et al. (2017) used fitted spatial autoregressive models to demonstrate that the higher the levels of resident contact, the higher the levels of trust and reciprocity are thus lower crime rates. They went on to point out that when these types of routine activities between residents are lower, and when there are higher numbers of nonresidents people in an area, the higher the overall crime rates are. These ecological processes demonstrate that when people are more connected to a community, and to each other, the lower crime rates will be (Browning et al., 2017; MacDo- 
nald et al., 2012; Ridgeway \& MacDonald, 2016).

Los Angeles has a very high immigrant population. It is widely believed in the general population that the higher the immigration rates the higher the crime rates, but many studies have not found this to be the case. It is not immigration per se that is associated with crime, it has more to do with matters pertaining to poverty, social capital, routines activities, the transitional nature of communities, social disorganization, and so forth (Browning et al., 2017; Burchfield \& Silver, 2013; Chang \& Lau, 2016; Ridgeway \& MacDonald, 2016). Macdonald et al. (2013) found that the higher the levels of assimilation among immigrants the lower the crime rates are in any given area. Through least squares regression modeling they found that the higher the rates of immigration in Los Angeles the lower the overall crime rates are as long as certain variables were factored out. For instance, the researchers noted that it is more likely the transitional nature of lower-income communities that make them more susceptible to higher crime, not immigration rates per se. It may be more due to the nature of lower-income areas than anything else. For example, poor neighborhoods have higher rates of off-premise alcohol outlets (e.g., liquor stores) than higher-income neighborhoods (Gorman, 2017). Gorman found in his work that the greater the densities of outlets that sell alcohol the greater the rates of violence in those general areas. There is more to crime than just the availability of alcohol, of course, but the data does suggest a correlation between the two.

There has also been a significant body of research done on hate crimes in Los Angeles. Los Angeles is well known for having certain areas that have a disproportionately high number of homosexual and transgendered individuals. Gays and lesbians are at relatively higher risk of being attacked than their heterosexual neighbors (Stotzer, 2008). Stotzer noted that approximately $3 \%$ of all of the lesbian, gay, and bisexual men and women in this nation live in Los Angeles county. In her work she explained that most hate crimes in Los Angeles county took place in public locations in south or west Los Angeles where there is a high racial minority population and a high level of poverty. Around 13 out of every 100,000 LGB individuals is the victim of a hate crime, and most of these crimes are against males in public places (Stotzer, 2010). Burks et al. (2018) found that many gay, lesbian, and bisexual individuals have higher than average level of stress and anxiety due to their awareness of the potential for being the target of a hate crime. From their sample of 336 urban LGB participants they found that 1 out of 3 have been the victims of a hate crime, typically of an interpersonal and violent nature. These rates are similar to what other researchers have found regarding violent crimes committed against LGB individuals (Stotzer, 2008; Stotzer, 2010).

Other important factors play into the crime rates and risk factors of victimization that can be seen across Los Angeles county. According to Kelly, Merrill, Shumway, Alvidrez, and Boccellari (2010) the major risk factors that are correlated to being victimized include being poor, living in the inner-city, living in urban public housing, being exposed to ongoing community violence, and being 
marginally housed or homeless. The researchers explained that disadvantaged inner-city populations are at the highest risk of being victimized, which is substantially compounded when correlated with poor coping skills, mental health problems, and pronounced psychosocial stressors (Kelly et al., 2010). Additional risk factors include higher numbers of marijuana dispensaries, which has been associated with predatory crime and increased opportunities for crime (Contreras, 2017), drug use and being violently victimized (Hawke, Jainchill, \& DeLeon, 2003), and being a community-dwelling elderly individual in Los Angeles and being financially abused (Wood et al., 2014). Research has also found that Black elderly men and women living in poor urban neighborhoods are especially at risk for being victimized and live in higher than average levels of fear (Bazarghan, 1994).

There are other important things to consider when trying to make sense of crime in the greater Los Angeles area. For instance, Los Angeles can get very hot during certain times throughout the year. Using data from the Los Angeles Police Department, Dong, Cao, Siercke, Wilber, and McCalla (2017) found through nonparametric analyses that higher temperatures in the Los Angeles area was connected to increased hostility, violent crimes, and property crimes. Although the exact nature of this is not fully understood, it has been widely shown across many national studies that rising temperatures are associated with certain kinds of aggressive behaviors and crimes. There has also been a strong link made between the built environment and crime in Los Angeles. Anderson, MacDonald, Bluthenthal, and Ashwood (2013) analyzed areas in Los Angeles that are primarily zoned for commercial use versus areas that are primarily zoned for residential use and they found a clear link between higher levels of commercial zoning and higher crime rates. They concluded that mixing in residential zoning with commercial zoning helps lower overall crime rates in those areas that are highly commercialized.

As one can see from the relevant literature there are many different factors that play into urban crime and victimization. Los Angeles county is a very populated region with over 10 million residents, and it is getting more populated each year (MacDonald et al., 2012; Stotzer, 2010). Crime has been increasing across the Los Angeles area for many different reasons (e.g., sheer numbers of people, unemployment, drug use, homelessness, gangs, etc.). Gender also plays a role. Women living in urban areas generally have higher rates of fear of being victimized than men generally do (Riger \& Gordon, 1983). There are various reasons for this, but much of it has to do with inequitable power in society, financial dependence, lack of social control, and living with the perceived (or actual) threat of male violence (Burks et al., 2018; Chang \& Lau, 2016; Riger \& Gordon, 1983). Some individuals are at increased risk of being victimized due to their positions in the social structure, their lifestyles, their social status, their living situations, etc. (Burchfield \& Silver, 2013; Kelly et al., 2010; Ridgeway \& MacDonald, 2016; Rosenfeld, Vogel, \& McCuddy, 2018). Either way, anyone can suddenly find themselves being the victim of a crime. There are certain factors that 
increase one chances of being victimized and this review has highlighted a number of them to keep in mind throughout this investigation. Los Angeles is a great area to live in and it offers much to those that reside here. Los Angeles also has major problems with almost every type of crime category. There is much to be investigated and analyzed in regard to this particular county's ongoing social and criminal problems.

\section{Methodology}

\subsection{Research Design}

This study collected data through primary survey research from local residents of the Los Angeles, California region. Survey respondents were currently residing in numerous cities/towns across the greater Los Angeles area (e.g., Van Nuys, North Hollywood, Reseda, Santa Monica, Montebello, Burbank, etc.). Respondents were intentionally recruited from different regional cities so as to get a broader understanding of crime across the wider Los Angeles area-as opposed to collecting data from just a single city. The data for the study was collected in a nonrandom manner. To be eligible for the study participants needed to currently live in the greater Los Angeles area and they needed to be at least 18 years of age. No minors were included in the study. The survey instrument took less than 5 minutes to complete and there was no compensation given for participation. Consent was given by their willingness to fill out the survey. The survey had a quantitative design and asked about key demographics variables relevant to this study (e.g., gender, social class, ethnicity) that will assist in making inferences about group differences and experiences. The survey asked about the types of crimes committed against the respondents, whether or not they knew the perpetrators, how respondents felt about living in Los Angeles, how old they were when they were victimized, and so forth. Examples of some of the questions include, "Have you ever been the victim/target of any type of crime?" "Did you know the person(s) that victimized/targeted you?" "How safe do you feel living in the Los Angeles or surrounding areas?" "What was your age(s) when the crime(s) were committed?" A single Likert-type scale ranging from 1 to 5 was used to get a sense of how safe residents feel living in Los Angeles (e.g., $1=$ Not at all safe, $3=$ Neutral, $5=$ Very Safe). Other relevant questions were asked concerning respondent's perceptions about crime and living in Los Angeles, victimization, and crime in general.

\subsection{Participant Information}

The research included 218 participants that all currently live in the greater Los Angeles area. The final sample included 135 women (62\%), 81 men (37\%), 1 respondent that identified as "other" $(.5 \%)$ and one survey where the respondent failed to answer that particular question (.5\%). The age of the respondents was diverse, ranging from 18 to 87 . See Table 1 for the breakdown of the ages of the 
study's respondents. The majority of respondents were in their 20 's skewing the data toward younger adults. Table 2 displays the ethnic breakdown of the respondents. Hispanics made up the majority of respondents in the study. This is arguably proportionate with the general demographics across Los Angeles in which Hispanics are the counties majority population. None of the participants identified as Native American. The descending order of the sample size in regard to ethnicity is generally reflective of the wider demographic characteristics across the greater Los Angeles area.

The mean length of residency in the Los Angeles area was 23 years. The range of length of residency in the Los Angeles area was from a minimum of 1 year up to a maximum of 66 years. Many of the respondents stated that they have lived in the Los Angeles area their entire lives. In regard to social class, 99 respondents self-identified as being from the lower/working-class (45.4\%), 116 identified as being from the middle-class (53.2\%), and 3 stated that they are in the upper-class (1.4\%). The majority of Americans and Angelinos do identify as being middle-class, and then working-class, so this is generally reflective of the wider population. The sample size of upper-class respondents is quite small, so any statements made in this regard must be cautious and regarded as merely tentative. The sample size of the middle-class and lower/working-class respondents is large enough to make statistically confident statements and inferences. Further information regarding the respondents and their various experiences with crime, as well as their perceptions of crime, will be analyzed in the following sections.

Table 1. Age of respondents.

\begin{tabular}{ccc}
\hline Age & Size & Percentage of Sample \\
\hline $20-29$ & 145 & $66.5 \%$ \\
$30-39$ & 20 & $9.2 \%$ \\
$40-49$ & 18 & $8.3 \%$ \\
$50-59$ & 7 & $3.2 \%$ \\
$60-69$ & 9 & $4.1 \%$ \\
$70-79$ & 5 & $2.3 \%$ \\
$80+$ & 1 & $.5 \%$ \\
\hline
\end{tabular}

Table 2. Ethnicity of respondents.

\begin{tabular}{ccc}
\hline Ethnicity & Size & Percentage of Sample \\
\hline Hispanic & 130 & $59.6 \%$ \\
White & 50 & $22.9 \%$ \\
Black & 13 & $6.0 \%$ \\
Asian & 9 & $4.1 \%$ \\
Middle Eastern & 8 & $3.7 \%$ \\
Other & 8 & $3.7 \%$ \\
\hline
\end{tabular}




\subsection{Analysis of the Data}

Multiple analyses were performed on the data. Both descriptive and inferential analyses were conducted with the use of the statistical software program SPSS 24. A number of descriptive analyses were performed across the highlighted categorical variables (e.g., mean scores, standard deviations, etc.). The nominal and ordinal level variables were coded in SPSS for proper analysis. The continuous level data was directly placed into the database for analysis. The one-way analysis of variance (ANOVA) was utilized to detect any potential significant differences between clustered age groups, social class, and ethnicity. Multiple correlations were performed to detect any significant associations between key variables and scale items (e.g., Pearson's r, gamma, Spearman's rho, Kendall's tau, Cramer's V, Phi). Appropriate crosstabulations and Chi-square analyses were also run on appropriate categorical variables. The level of statistical significance was set at the standard .05 for all analyses performed. The direction of significance was two-tailed across all tests performed. Any result that had a higher probability of chance occurrence than the established .05 level was deemed statistically insignificant and was treated accordingly.

If any questionnaire item was left blank it was not included in any analysis pertaining to that specific variable or item. None of the surveys had to be discarded for clearly fabricated responses or for responses that were unclear or nonsensical. All of the 218 questionnaires that were filled out were deemed to be valid and useful for the purposes of this study. None of the questionnaires has to be discarded for questionable or unclear responses. All questionnaires appeared to be answered in a deliberate and truthful manner. Some types of crimes needed to be clustered together to create common categories. For example, fraud and identity theft would be placed into the common category of white-collar crime. Groping, rape, and sexual assault were all placed under the general category of a sex crime. This was necessary so that proper analyses could be made and so that there were not too many disconnected types of crimes and non-analyzable categories. Respondents generally appeared to have a clear understanding of what the survey was about and how to properly answer the questions presented.

\section{Findings of the Study}

\subsection{Illuminating Descriptive Statistics}

When respondents were asked if they have ever been the targets of any type crimes while they have lived in the Los Angeles area the majority stated that they have been $($ Yes $=65.7 \%$, No $=34.3 \%)$. Respondents were not asked about any types of crimes committed against them when they were living in another area in California or in another state. When asked if they have been targeted on more than one occasion the majority stated that they have not been $(\mathrm{No}=54.5 \%$, Yes $=45.5 \%)$. The average respondent was targeted 1.84 times since they have lived in the Los Angeles area. The majority of respondents were targeted between 1 to 
2 times $(80.4 \%)$. One respondent claimed to have been targeted 10 times since living in the general region. Women were most often targeted in their 20 's $(\mathrm{M}=$ 22 years of age) and were targeted on average 1.85 times. Men had a mean target age of 24 years and their average number of times being targeted was 1.83 . The single respondent that identified their gender as "other" was first targeted at 16 years of age and has been the direct target of criminal behavior 2 times.

The general patterns across ethnic groups revealed the following findings. Table 3 displays the data for ethnicity, mean age, and the average numbers of times respondents were targeted. Those from the lower/working-class had an average target age of 20.7 and were targeted an average of 2.05 times. Those from the middle-class had an average target age of 24.0 and an average number of times being targeted of 1.67 times. Upper-class respondents had an average target age of 50 and have been victimized an average of 1.50 times.

Most of the respondents that have been victimized by one or more criminal acts do not know the person(s) that targeted them (68.5\%). Approximately $17 \%$ of the respondents did know the person(s) that targeted them. Approximately $15 \%$ of the victimized respondents stated that they knew the perpetrator(s) of the crimes committed against them on one or more occasions but did not know the perpetrator(s) on other occasions. When asked how safe they feel living in Los Angeles the most common response of respondents was that they were neutral on the matter $(n=87,39.9 \%)$. The remainder of the respondents felt that they were relatively safe $(n=73,33.5 \%)$, were relatively not safe $(n=28,12.8 \%)$, were very safe $(n=23,10.6 \%)$, and were not at all safe $(n=7,3.2 \%)$. When asked how they felt about crime in the Los Angeles area many respondents seemed to feel that things were not changing $(n=104,44.7 \%)$, while 60 respondents $(27.5 \%)$ felt that crime rates were improving, and 54 respondents felt that crime was actually getting worse across the area (24.8\%).

\subsection{Types of Crimes}

Out of the 140 respondents that stated that they have been the target of one or more criminal acts there was a wide range of crime types noted. The single most common type of crime was robbery. See Table 4 for the breakdown of the types of crimes committed against the respondents. These are the findings for those that were targeted on one occasion. The largest single response by those that have been targeted (on one or more occasions) was that they have actually faced multiple types of criminal acts committed against them ( $\mathrm{n}=55,25.2 \%)$. The most frequently listed types of crimes committed against those that have dealt with multiple acts were robbery, violent, property, motor vehicle, and burglary.

\subsection{Parametric Measures}

A one-way analysis of variance did reveal group differences in regard to the typical ages when residents were targeted, $\mathrm{F}(5,122)=3.55, p=.005$. Post hoc tests found significant differences in regard to Hispanic and White residents, with a 
Table 3. Summary data on ethnicity and victimization.

\begin{tabular}{rcc}
\hline Ethnicity & Mean Age & Mean Times Targeted \\
\hline Hispanic & 20.4 & 1.83 \\
White & 24.6 & 2.17 \\
Black & 26.4 & 1.72 \\
Middle Eastern & 26.4 & 1.25 \\
Asian & 15.6 & 1.60 \\
Other & 17.3 & 1.75 \\
\hline
\end{tabular}

Table 4. Crimes committed against respondents targeted on one occasion.

\begin{tabular}{ccc}
\hline Crime Type & Size & Percentage of Sample \\
\hline Robbery & 23 & $10.6 \%$ \\
Motor Vehicle Theft & 11 & $5.0 \%$ \\
Burglary & 11 & $5.0 \%$ \\
Vandalism & 9 & $4.1 \%$ \\
White-Collar & 9 & $4.1 \%$ \\
Violent & 8 & $3.7 \%$ \\
Sexual & 6 & $2.8 \%$ \\
Property & 6 & $2.8 \%$ \\
Larceny-Theft & 1 & $.5 \%$ \\
\hline
\end{tabular}

mean difference of -7.41 years (Tukey HSD sig. $=.005$; Bonferroni sig. $=.005$; LSD sig. $=.000)$. These findings reveal that Hispanics were more likely to victimized at a younger age that White residents. Whites were also more likely to be older when they are victimized than Middle Eastern residents, with a mean difference of 9.63 years (LSD sig. $=.026$ ). Those respondents that identified their ethnicity as "Other" were more likely to be victimized at older ages than both Hispanic residents (mean difference $=11.29$ years; LSD sig. $=.05$ ), as well as Middle Eastern residents (mean difference $=13.50$; LSD sig. $=.05$ ). A further ANOVA analysis did not reveal any discernible differences between ethnic groups and the number of times targeted for crimes, $\mathrm{F}(5,137)=.948, p=.452$. Independent samples T-tests were run on the variables of gender, ages when targeted, and number of times targeted. No significant groups differences were revealed in the data (ages: $\mathrm{t}=.026$, sig. $=.220$; number of times targeted: $\mathrm{t}=.462$, sig. $=.939)$. There were also no significant group differences found in the analysis of social class and number of times targeted, $\mathrm{F}(2,140)=1.46, p=.235$.

\subsection{Correlational Measures}

Multiple measures of correlation revealed several significant associations between certain variables of interest. In regard to the respondent's feelings about 
crime in Los Angeles and feeling safe living in Los Angeles, Kendal's tau produced a significant negative association $\left(\mathrm{r}_{\mathrm{T}}=-.251, p=.000\right)$, as did a Spearman's rho analysis $\left(\mathrm{r}_{s}=-.285, p=.000\right)$. This finding essentially shows that those residents that feel that crime is getting worse in the Los Angeles area also relatively feel unsafe, while those that feel that crime is improving tend to feel relatively safe in the area. When asked about how residents feel about crime in Los Angeles and how safe they generally feel, gamma also produced a significant negative correlation ( $\mathrm{g}=-.372, p=.000$ ). There also appears to be a significant association between gender and knowing the perpetrator $(\phi=.272, p=.031 ; \mathrm{V}$ $=.193, p=.031)$. Women were more likely to know the perpetrator of the crimes than the men. Phi and Cramer's V revealed a significant association between ethnic groups and the likelihood of being targeted (e.g., Hispanic and Asian; $\phi$ $=.236, p=.036 ; \mathrm{V}=.236, p=.036)$. Phi and Cramer's $\mathrm{V}$ also revealed significant associations between ethnicity and feeling safe (or unsafe) in Los Angeles ( $\phi$ $=.459, p=.001 ; \mathrm{V}=.230, p=.001$ ). Hispanics and Whites generally tend to feel somewhat safe, while Middle Eastern residents tend to generally feel less safe living in the Los Angeles area.

\subsection{Crosstabulations}

A number of crosstabulations were run on the data which produced significant results. First, when women and men were asked if they knew the person(s) that targeted them the women were much more likely to respond that they did (23.8\%) than the men (6.9\%). A chi-square analysis produced a statistically significant result $\left(X^{2}=10.62, p=.031\right)$ which implies that women in the population are more likely to know the people that commit crimes against them. Table 5 breaks down the data in regard to gender and lived experiences. Women were also more likely to state that they felt that crime was getting worse in Los Angeles and they also felt slightly less safe overall than the men. Men appeared to be the targets of criminal acts at higher rates than women. Of the residents that have been targeted for any type of crime, women were slightly more likely to have been targeted one more than one occasion.

In regard to ethnic differences, Hispanics were the targets of criminal acts at a rate of 77 out of $128(60.2 \%)$, Whites at a rate of 35 out of $48(72.9 \%)$, Blacks at a rate of 11 out of 12 (91.7\%), Asians at a rate of 5 out of 9 (55.6\%), Middle Eastern at a rate of 8 out of $8(100 \%)$, and "Others" at a rate of 4 out $8(50 \%)$. A chi-square test resulted in a statistically significant result $\left(X^{2}=11.91, p=.036\right)$ which shows that ethnic groups vary in terms of their rates of being victimized. Black and Middle Eastern residents have significantly higher rates compared to the other groups. Asian residents have significantly lower victimization rates overall. Groups also varied in regard to how unsafe they felt in the Los Angeles area. Middle Eastern respondents were the most likely to feel relatively unsafe in the Los Angeles area (50\%), followed by Black residents (38.5\%), "Other" (25\%), Hispanic (13.8\%), and White (12\%). None of the Asian respondents felt unsafe 
in the area. These findings produced a significant chi-square $\left(X^{2}=46.0, p\right.$ $=.001)$ which suggests that certain ethnic groups do feel less safe living in the Los Angeles area.

Social class differences were looked at in regard to certain variables. Table 6 summarizes the findings across the lived experiences and feelings about crime in Los Angeles. Crimes rates were relatively similar across all social classes in regard to being targeted for criminal acts and general perceptions across most variables. Some notable differences were found in relation to feeling safe or unsafe and beliefs about crime getting better or worse across greater Los Angeles.

\section{General Discussion}

The current study brought forth some interesting findings that seem to be in line with what can be found in the broader literature. Los Angeles and its surrounding cities have a clear problem with crime and it does not appear to be getting any better (Area Vibes, 2018; Chang \& Lau, 2016; Neighborhood Scout, 2018). This study found that the majority of residents across greater Los Angeles have been the victims of a criminal act on one or more occasions (65.7\%). Some of the respondents have only lived in the Los Angeles are for 1 to 5 years, so it stands to reason that the longer they live here the more likely they will be targeted for some type of crime at some point. The types of crimes that were highlighted in their responses are also in line with what other studies have found, such as with violent crimes and property crimes (Browning et al., 2017; Chang, 2017; Easter, 2017). None of the respondents mentioned anything about any type of hate crime committed against them, so this was not in line with what was discussed earlier in the articles about the prevalence of hate crimes across Los Angeles

Table 5. Gender differences in experiences and perceptions.

\begin{tabular}{ccc}
\hline Prompt & Women & Men \\
\hline Crime is getting worse in L.A. & $28.1 \%$ & $19.5 \%$ \\
Living in L.A. is not safe & $17.8 \%$ & $13.4 \%$ \\
Targeted for criminal acts & $63.6 \%$ & $70.0 \%$ \\
Targeted on more than one occasion & $47.6 \%$ & $41.4 \%$ \\
\hline
\end{tabular}

Table 6. Social class differences in experiences and perceptions.

\begin{tabular}{cccc}
\hline Prompt & Working-Class & Middle-Class & Upper-Class \\
\hline Targeted for crimes & $65.7 \%$ & $65.8 \%$ & $66.7 \%$ \\
Targeted more than once & $47.0 \%$ & $44.0 \%$ & $50.0 \%$ \\
Crime is getting worse in L.A. & $26.3 \%$ & $23.3 \%$ & $33.3 \%$ \\
Crime is improving in L.A. & $28.3 \%$ & $27.6 \%$ & $0.0 \%$ \\
Feel unsafe living in L.A. & $17.2 \%$ & $14.7 \%$ & $33.3 \%$ \\
Feel safe living in L.A. & $36.4 \%$ & $50.9 \%$ & $33.3 \%$ \\
\hline
\end{tabular}


(Burks et al., 2018; Stotzer, 2008; Stotzer, 2010). An additional study specifically looking at crimes committed against LGBT residents could help to better highlight this particular problem. With this said, the study did bring forth some illuminating data regarding gender, age, ethnic, and social class differences.

The data produced in this study did show that age is a factor when it comes to being targeted for crimes. Younger respondents were more likely than older respondents to be victimized (e.g., violent, sexual). Most of the people in the study reported being first victimized either in their teenage years or in their early 20 's. This is in accordance with the literature in regard to younger people being more prone to being victimized in certain kinds of ways (e.g., violent crimes, drug-related crimes) than older people (Hawke et al., 2003; Wood et al., 2014). With this said, it is important to note that older individuals are more likely to be targeted for certain types of crimes than younger people (e.g., fraud, identity theft). Young women were much more likely to report being sexually targeted than any other group in the study. This is also aligned with larger statistics collected across the county looking at sex-related crimes (Neighborhood Scout, 2018; Riger \& Gordon, 1983; Stotzer, 2010). Fear of being sexually victimized does not appear to be a concern or issues with male residents across Los Angeles. The exception to this may revolve around homosexual males (Stotzer, 2008; Stotzer, 2010), but it does not seem to be a concern or issue with heterosexual males living in this area.

The average respondent has been targeted approximately 2 times. In regard to a single criminal act where only one type of crime was committed, robbery was the most common response (10.6\%). Robbery typically involves the taking of personal property by force or threat, so this could be clustered within the violent crime category. It was difficult to dissect and discuss all of the types of crimes and various rates due to the fact that many of the respondents that have been targeted for crimes listed a number of different crimes that they have had to deal with. For instance, one respondent stated that they had been the victim of assault and battery, motor vehicle theft, and sexual assault. Another respondent stated that he has had property, robbery, and motor vehicle theft crimes committed against him. These types of clusters made it difficult to parse out which types of crimes were being committed against which types of residents. With this said, the findings did bring forth the importance of paying attention to relevant demographic variables and how they may play into which types of people may be victimized in which kinds of ways. This can be connected to the literature that has looked at these types of problems and concerns (Bazarghan, 1994; Burchfield \& Silver, 2013; Burks et al., 2018; Chang, 2017; MacDonald et al., 2012). Around one in four respondents in the current study (25.2\%) stated that they have been targeted on multiple occasions and have been the victims of different types of crimes.

It was also interesting to see how different ethnic groups perceived Los Angeles and what their various experiences were with criminal targeting. Middle 
Eastern and Black residents had distinct views and experiences when it comes to crime and safety. The majority of these respondents have been victimized in one way or another and this appears to have had some kind of impact on their feelings of safety living in the Los Angeles area. Hispanic and White respondents were similar across many categories, such as rates of being targeted, perceptions about safety, etc., but they did differ in regard to age at first victimization. Hispanics were around 7 years younger than Whites when first targeted. Asian respondents had the lowest victimization rates overall and this probably has had a significant impact on their feeling relatively safe living in the general area. Asian respondents were also more likely to live in middle-class or upper-class areas, which could also be linked to better security and safety in living conditions. Certain types of crimes and social classes are inversely connected for the most part, and the most dangerous types of crimes do tend to happen in lower-class neighborhoods and communities (Anderson et al., 2013; MacDonald et al., 2012; Rosenfeld et al., 2018). This is not to say that crime does not occur in rich areas, but differences can be seen in the types of crimes often committed across class boundaries (e.g., gang violence, white-collar crime; Browning et al., 2017; Kelly et al., 2010; Moore \& Recker, 2017).

It is not clear whether or not the respondents were informed about actual crime rates across greater Los Angeles, so this cannot be inferred here. What was of interest was how respondents perceived things to be. Many respondents felt that crime was not really changing across the area. There was a split between some respondents feeling that things are getting worse, while others felt that things are getting better. A more qualitative inquiry would be needed to parse out these perceptual differences and why they feel the ways that they do. Many respondents also felt relatively neutral of their overall safety (40\%), while $44 \%$ did feel relatively safe, and $16 \%$ generally did not feel safe living in the Los Angeles area. There are certain demographic variables that need to be taken into account to be able to better make sense as to why some residents feel safe while others do not (Bazarghan, 1994; Browning et al., 2017; MacDonald et al., 2012). This study included a high number of respondents that claimed to have never been victimized while living in Los Angeles ( $\mathrm{n}=73,33.5 \%)$ so it may make sense that they have not cultivated the fear of being victimized and have not been directly shaped by certain acts committed against them. Those that have been victimized appeared to lean more in the direction that crime in Los Angeles is a problem and that they a less safe overall. This could clearly be seen in the responses provided by the Middle Eastern and Black residents included in this study. This also holds with the larger literature and what has been found on these matters (Chang \& Lau, 2016; Kelly et al., 2010; Riger \& Gordon, 1983).

In the final analysis it appears that crime is a real problem and concern across Los Angeles. The majority of residents included in this study have claimed to have been criminally targeted on one or more occasions since they have lived in this general area. It stands to reason that the longer residents have lived here the 
more likely they are to have been targeted at least once. Residents were split in regard to how they generally felt about crime in Los Angeles and their overall safety. Regardless of how people feel about crime in Los Angeles, it is a major problem compared to most other urban areas across the nation (Area Vibes, 2018; Burchfield \& Silver, 2013; Neighborhood Scout, 2018) and there are clearly many improvements that need to be made (Chang \& Lau, 2016; Chang, 2017; Easter, 2017; MacDonald et al., 2012). This study has brought forth some useful findings to help better illuminate what is taking place across greater Los Angeles and how local residents feel about current conditions.

\section{Research Limitations}

It is not clear from the data why certain residents feel the ways that they do about crime, about their safety, and about victimization in general. To be able to make more valid statements about upper-class residents the study would need to have a larger sample size for this specific category of social class. Another limitation revolves around the ages of the respondents. Most of the respondents were under 50 years of age (89.9\%). All respondents were currently living in the Los Angeles area and no restrictions were made on how long they had to live here or where (which specific city) they had to live in. Collecting data from those living in more dangerous (crime prone) areas across the territory may result in more accurate data in regard to crime and victimization.

\section{Conclusion}

Crime and victimization in Los Angeles is a serious social issue that demands much more attention. Residents in the greater Los Angeles area have a relatively high chance of being the targets of criminal acts at some point. Many will be victimized on numerous occasions. Unfortunately, some will be chronic victims of various types of crimes and violent acts. We must do all that we can to ensure the safety of local residents and to try and figure out the most effective ways to reduce crime across the wider city. Los Angeles and its surrounding cities offer many great things for its residents. But it also has its problems. We need to promote healthier neighborhoods and larger communities. Problems with drugs, gang violence, theft, poverty, homelessness, etc., must all be better addressed by those with power and influence. Increased funding for certain problems and issues (e.g., housing, drug rehabilitation, domestic violence, and so forth) and improved policies that directly and effectively address these ongoing problems is a must. With more effort and focus, this major national city and its surrounding territories can become an even better and safer place to reside and live out our lives.

\section{Contributions and Future Research}

Crime across Los Angeles is a major problem. This study has brought forth some additional information to help better illuminate what is taking place and how 
local residents feel about what is taking place. The study has demonstrated that crime is a serious problem and that most residents will be the targets of crime at one point or another. The study had also dissected important demographic variables and how different social groups are affected differently by criminal acts. The study has also shown that there are also many similarities across social groups, how they are impacted by crime, and how they feel about crime in Los Angeles. Future studies could take a closer look at how chronic victims perceive crime and safety in Los Angeles. Further work in this area could also pay closer attention to age and victimization. The population across Los Angeles county, as well as the nation at large, is getting older. With this being the case we can only expect to see many more elderly men and women being the targets of criminal acts. This is especially true in regard to financial abuse and certain types of white-collar crimes. It is also important to pay attention to the factors that contribute to one being victimized (e.g., drug use, intimate relations, domestic violence, routine activities, etc.). Additional research in this area could help to reduce both one-time and chronic victimization. Potential research in this important and applied area is, for all practical purposes, unlimited.

\section{References}

Anderson, J. M., MacDonald, J. M., Bluthenthal, R., \& Ashwood, J. S. (2013). Reducing Crime by Shaping the Built Environment with Zoning: An Empirical Study of Los Angeles. University of Pennsylvania Law Review, 161, 699-756.

Area Vibes (2018). Reported Annual Crime in Los Angeles. https://www.areavibes.com

Bazarghan, M. (1994). The Effects of Health, Environmental, and Socio-Psychological Variables on Fear of Crime and Its Consequences among Urban Black Elderly Individuals. The International Journal of Aging and Human Development, 38, 99-115. https://doi.org/10.2190/FHQY-5T3L-GADM-PUD0

Browning, C. R., Calder, C. A., Boettner, B., \& Smith, A. (2017). Ecological Networks and Urban Crime: The Structure of Shared Routine Activity Locations and Neighborhood-Level Informal Control Capacity. Criminology: An Interdisciplinary Journal, 55, 754-778. https://doi.org/10.1111/1745-9125.12152

Burchfield, K. B., \& Silver, E. (2013). Collective Efficacy and Crime in Los Angeles Neighborhoods: Implications for the Latino Paradox. Sociological Inquiry, 83, 154-176. https://doi.org/10.1111/j.1475-682X.2012.00429.x

Burks, A. C., Cramer, R. J., Henderson, C. E., Stroud, C. H., Crosby, J. W., \& Graham, J. (2018). Frequency, Nature, and Correlates of Hate Crime Victimization Experiences in an Urban Sample of Lesbian, Gay, and Bisexual Community Members. Journal of Interpersonal Violence, 33, 402-420. https://doi.org/10.1177/0886260515605298

Chang, C. (2017). In Los Angeles, Homicides Are Down, but Violent Crime Is up for the Fourth Year in a Row. The Los Angeles Times. http://latimes.com

Chang, C., \& Lau, M. (2016). Violent Crime in L.A. Jumps for Third Straight Year as Police Deal with Gangs, Homeless Issues. The Los Angeles Times. http://www.latimes.com

Contreras, C. (2017). A Block-Level Analysis of Medical Marijuana Dispensaries and Crime in Los Angeles. Justice Quarterly, 34, 1069-1095.

https://doi.org/10.1080/07418825.2016.1270346 
Dong, K., Cao, Y., Siercke, B., Wilber, M., \& McCalla, S. G. (2017). Advising Caution in Studying Seasonal Oscillations in Crime Rates. PLOS One, 12, 1-15. https://doi.org/10.1371/journal.pone.0185432

Easter, M. (2017). Crime Rates down in California, up in L.A. County, during a Period of Criminal Justice Reform. The Los Angeles Times. http://www.latimes.com

Gorman, D. M. (2017). Violent Crime Redistribution in a City Following a Substantial Increase in the Number of Off-Sale Alcohol Outlets: A Bayesian Analysis. Drug and Alcohol Review, 37, 348-355. https://doi.org/10.1111/dar.12636

Hawke, J. M., Jainchill, N., \& De Leon, J. (2003). Posttreatment Victimization and Violence among Adolescents Following Residential Drug Treatment. Child Maltreatment, 8, 58-71. https://doi.org/10.1177/1077559502239609

Kelly, V. G., Merrill, G. S., Shumway, M., Alvidrez, J., \& Boccellari, A. (2010). Outreach, Engagement, and Practical Assistance: Essential Aspects of PTSD Care for Urban Victims of Violent Crime. Trauma, Violence, and Abuse, 11, 144-156. https://doi.org/10.1177/1524838010374481

Macdonald, J. M., Hipp, J. R., \& Gill, C. (2012). The Effects of Immigrant Concentration on Changes in Neighborhood Crime Rates. Journal of Quantitative Criminology, 29, 191-215. https://doi.org/10.1007/s10940-012-9176-8

Moore, M. D., \& Recker, N. L. (2017). Social Capital Groups and Crime in Urban Counties. Deviant Behavior, 38, 655-677. https://doi.org/10.1080/01639625.2016.1197609

Neighborhood Scout. (2018). Los Angeles Crime Rates and Statistics. https://www.neighborhoodscout.com/ca/los-angeles/crime

Ridgeway, G., \& MacDonald, J. M. (2016). Effect of Rail Transit on Crime: A Study of Los Angeles from 1988 to 2014. Journal of Quantitative Criminology, 33, 277-291. https://doi.org/10.1007/s10940-016-9296-7

Riger, S., \& Gordon, M. T. (1983). The Impact of Crime on Urban Women. Issues in Mental Health Nursing, 5, 139-156. https://doi.org/10.3109/01612848309009437

Rosenfeld, R., Vogel, M., \& McCuddy, T. (2018). Crime and Inflation in U.S. Cities. Journal of Quantitative Criminology, 3, 1-16.

Stotzer, R. L. (2008). Gender Identity and Hate Crimes: Violence against Transgender People in Los Angeles County. Sexuality Research and Social Policy, 5, 43-52. https://doi.org/10.1525/srsp.2008.5.1.43

Stotzer, R. L. (2010). Seeking Solace in West Hollywood: Sexual Orientation-Based Hate Crimes in Los Angeles Country. Journal of Homosexuality, 57, 987-1003. https://doi.org/10.1080/00918369.2010.503506

Wood, S., Rakela, B., Liu, P. J., Navarro, A. E., Bernatz, S., Wilber, K. H., Allen, R., \& Homier, D. (2014). Neuropsychological Profiles of Victims of Financial Elder Exploitation at the Los Angeles County Elder Abuse Forensic Center. Journal of Elder Abuse and Neglect, 26, 414-423. https://doi.org/10.1080/08946566.2014.881270

World Population Review (2018). Los Angeles, California Population 2018. https://www.worldpopulationreview.com/us-cities/los-angeles-population 